\title{
Evaluation Of The Efficacy Of Hepatitis B Vaccine For Children In Misurata Region, Libya
}

\author{
Faraj Ali AbuShaala and Rima Mustafa Lapez \\ Department of Microbiology, Faculty of Science, Misurata University, Libya
}

\begin{abstract}
Hepatitis B virus (HBV) is a blood borne and sexually transmitted virus. Rates of new infection and acute disease are highest among adults, but chronic infection is more likely to occur in persons infected as infants or young children aged 2-5 years old. Hepatitis B vaccination is the most effective measure to prevent HBV infection and its consequences. This study was aimed to evaluate the effectiveness of HBV vaccine in randomly selected children from Misurata province, Libya and personal factors associated with serologic evidence of the immune response. Serum samples for each participant were tested for the quantitative determination of anti-HBs antibody using Enzyme Linked Fluorescent Assay. The results of antibody response to hepatitis-B vaccine among children cases included in the current study, indicated that antibody decay occurs with time. In our study negative antibody response were observed in $21 \%$ and $17 \%$ among male and female children respectively whom were vaccinated according to the official vaccination schedule and their ages range was 2-5 years old. This negative percentages were increased to $27 \%$ and $29 \%$ in male and female children respectively whom age range was 6-8 years old. Children of age rangedfrom 9-12 years old the antibody response negative percentages were $33 \%$ and $25 \%$ in male and female children respectively. Antibody prevalence titer was higher in older male and female children than younger children as the antibody titers were 33, 25; 27,29; and 21, 17 respectively.
\end{abstract}

\section{INTRODUCTION}

Hepatitis is a general term meaning inflammation of the liver which can be caused by a variety of different viruses such as hepatitis A, B, C, D, E and G, as well as other agents. Hepatitis-B virus (HBV) infection is a global public health problem with approximately 400 million people chronically infected. Infection due to Hepatitis B virus results wide spectrum of liver diseases ranging from fulfillment hepatitis to cirrhosis and hepatocellular carcinoma. In addition, HBV carriers can transmit the disease for many years. Infection occurs very often in early childhood when it is asymptomatic and often leads to the chronic carrier state.

Despite advances in antiviral therapy, only a minority of chronic hepatitis B patients have a sustained response. Thus primary prevention by vaccination remains the main thrust in the control of hepatitis B infection (1).
Hepatitis B is caused by HBV, an enveloped virus containing a partially double stranded circular DNA genome, and classified within the family hepadnaviridae. The virus is composed of a $27 \mathrm{~nm}$ nucleocapsid core (HBcAg), surrounded by an outer lipoprotein coat (also called envelope) containing the surface antigen HBs Ag (2).

Most infected people look perfectly healthy and have no symptoms of disease, yet they may be highly infectious. HBV is transmitted through percutaneous or parenteral contact with infected blood, body fluids. and by sexual intercourse. $\mathrm{HBV}$ is able to remain viable on any surface it comes into contact with for about a week, e.g. table-tops, razor blades, blood stains, without losing infectivity. HBV does not cross the skin or the mucous membrane barrier. Some break in this barrier, which can be minimal and insignificant, is required for transmission (3). 
$\mathrm{HBV}$ is a large virus and does not cross the placenta, hence it cannot infect the fetus unless there have been breaks in the maternalfatal barrier, e.g., via amniocentesis. Still, pregnant women who are infected with HBV can transmit their disease to their babies at birth. If not vaccinated at birth, many of these babies develop lifelong HBV infections, and many develop liver failure or liver cancer later in life. Sexual intercourse with multiple partners or with persons who have multiple partners can be dangerous which can transmit the disease of the virus. Hepatitis B is the only sexually transmitted infection for which there is a protective vaccine (4).

This study was directed to evaluate the effectiveness of HBV vaccine in randomly selected individuals from Misurata province, Libya and personal factors associated with serologic evidence of the immune response.

\section{MATERIALS AND METHODS}

\section{Cases}

The study samples involved randomly selected 157 individuals which were composed of 82 boys and 75 girls. All the children received three doses of recombinant hepatitis $B$ vaccine between 1 and 6 months of age. The study sample comprised three age groups; the first group was 2 - 5 years (15boys, 14 girls), the second group was 6 - 8 years ( 28 boys, 27 girls) and the third group was $9-11$ years (39 boys, 34 girls).

Blood samples for serological analysis

About $3 \mathrm{ml}$ of venous blood were collected from each participant at different post-vaccination intervals (yearly till 12 years), following the completion of first, second and third dose of hepatitis B vaccine .The sera were removed from the tubes after clotting and centrifugation. Serum samples were divided into three labeled sterile tubes to avoid repeated freezing and thawing. Serum samples were stored frozen at $-20^{\circ} \mathrm{C}$ in the $\mathrm{Ibn}$ senaa laboratory before being analyzed.

Detection of Hepatitis B surface antibody (HBsAb) level.

The assay principle combines an enzyme immunoassay sandwich method with a final fluorescent detection (ELFA). The five reaction steps are performed automatically by the instrument. The reaction medium is cycled in and out of the SPR several times. Each step is followed by a wash cycle which eliminates unbound components. Once the assay is completed, results are analyzed automatically by the computer. Fluorescence is measured twice in the reagent strip's reading cuvette for each sample tested. The RFV (Relative Fluorescence value) is calculating by subtracting the background reading from the final results. The results are automatically calculated using calibration curves and are expressed in $\mathrm{mlU} / \mathrm{ml}$.

Statistical analysis of the results

The collected data was analyzed statistically by SPSS software version 13 and the statistical analysis was performed using Chi-square and student's test. Logistic regression models were used to assess the relationship between vaccine response and variables. Results were considered significant when $P<0.05$.

\section{RESULTS}

The results of antibody response to hepatitis-B vaccine among children cases included in the current study are presented in table (1). From this table we can say that antibody decay occurs with time. In our study negative antibody response were observed in 21 and $17 \%$ in male and female children respectively whom were vaccinated according to the official vaccination schedule and their age range was 2-5 years old. This negative 
percentages were increased to 27 and $29 \%$ in male and female children respectively whom age range was 6-8 years old. Finally in children with age range 9-12 years old the antibody response negative percentages were 33 and
$25 \%$ in male and female children respectively. We can conclude that clear decrease antibody titer (antibody decay) with the increase in the duration of post primary vaccination.

Table 1. Distribution of children cases according to antibody response to $\mathrm{HB}$ vaccine

\begin{tabular}{|c|c|c|c|c|c|c|c|c|}
\hline \multirow{4}{*}{$\begin{array}{c}\text { Age } \\
\text { (years) }\end{array}$} & \multirow{4}{*}{ Sex } & \multicolumn{6}{|c|}{ Antibody response } & \multirow{4}{*}{ Total } \\
\hline & & \multirow{2}{*}{\multicolumn{2}{|c|}{ Negative }} & \multicolumn{4}{|c|}{ Positive } & \\
\hline & & & & \multicolumn{2}{|c|}{ Weak positive } & \multicolumn{2}{|c|}{ Strong positive } & \\
\hline & & N. & $\%$ & N. & $\%$ & N. & $\%$ & \\
\hline \multirow{2}{*}{$2-5$} & Male & 6 & 21 & 3 & 10 & 6 & 21 & 15 \\
\hline & Female & 5 & 17 & 6 & 21 & 3 & 10 & 14 \\
\hline \multirow{2}{*}{$6-8$} & Male & 15 & 27 & 8 & 15 & 5 & 9 & 28 \\
\hline & Female & 16 & 29 & 4 & 7 & 7 & 13 & 27 \\
\hline \multirow{2}{*}{$9-12$} & Male & 24 & 33 & 6 & 8 & 9 & 12 & 39 \\
\hline & Female & 18 & 25 & 5 & 7 & 11 & 15 & 34 \\
\hline Total & & 84 & & 32 & & 41 & & 157 \\
\hline
\end{tabular}

N.B. \% were correlated to the total number of each children age group included in the study.

Also it was clear from the results obtained from tables (2) and (3) the effects of hepatitis B vaccination duration on seropositivity to antiHBs.We found that the protective anti-HBs induced by initial vaccination waned over time, and thus the proportion of nonprotected vaccinates.

Table 2. Effect of vaccine duration on seropositivity to anti-HBs among the studied male children group

\begin{tabular}{|c|c|c|c|c|c|c|c|c|}
\hline \multirow{4}{*}{$\begin{array}{c}\text { Duration of } \\
\text { vaccination / } \\
\text { years }\end{array}$} & \multicolumn{6}{|c|}{ Seropositivity } & \multirow{2}{*}{\multicolumn{2}{|c|}{ Total }} \\
\hline & \multicolumn{2}{|c|}{ Negative } & \multicolumn{4}{|c|}{ Positive } & & \\
\hline & \multirow{2}{*}{ N. } & \multirow{2}{*}{$\%$} & \multicolumn{2}{|c|}{ Weakly positive } & \multicolumn{2}{|c|}{ Strong positive } & \multirow[b]{2}{*}{ N. } & \multirow[b]{2}{*}{$\%$} \\
\hline & & & N. & $\%$ & N. & $\%$ & & \\
\hline 1.5 & 0 & 0.00 & 0 & 0 & 4 & 100 & 4 & 100 \\
\hline 2.5 & 3 & 60.00 & 1 & 20.00 & 1 & 20.00 & 5 & 100 \\
\hline 3.5 & 1 & 33.33 & 1 & 33.33 & 1 & 33.33 & 3 & 100 \\
\hline 4.5 & 2 & 67.00 & 1 & 33.00 & 0 & 0 & 3 & 100 \\
\hline 5.5 & 5 & 100 & 0 & 0 & 0 & 0 & 5 & 100 \\
\hline 6.5 & 6 & 54.55 & 4 & 36.36 & 1 & 9.09 & 11 & 100 \\
\hline 7.5 & 4 & 33.33 & 4 & 33.33 & 4 & 33.33 & 12 & 100 \\
\hline 8.5 & 4 & 44.44 & 1 & 11.11 & 4 & 44.44 & 9 & 100 \\
\hline 9.5 & 7 & 78.00 & 0 & 0 & 2 & 22.00 & 9 & 100 \\
\hline 10.5 & 8 & 72.73 & 2 & 18.18 & 1 & 9.09 & 11 & 100 \\
\hline 11.5 & 5 & 50.00 & 3 & 30.00 & 2 & 20.00 & 10 & 100 \\
\hline
\end{tabular}

N.B: \% were correlated to the total number of children male in each duration range. 
Table 3. Effect of vaccine duration on seropositivity to anti-HBs among the studied female children group

\begin{tabular}{|c|c|c|c|c|c|c|c|c|}
\hline \multirow{4}{*}{$\begin{array}{l}\text { Duration of } \\
\text { vaccination / } \\
\text { years }\end{array}$} & \multicolumn{6}{|c|}{ Seropositivity } & \multirow{3}{*}{\multicolumn{2}{|c|}{ Total }} \\
\hline & \multicolumn{2}{|c|}{ Negative } & \multicolumn{4}{|c|}{ Positive } & & \\
\hline & \multirow{2}{*}{ N. } & \multirow{2}{*}{$\%$} & \multicolumn{2}{|c|}{ Weakly positive } & \multicolumn{2}{|c|}{ Strong positive } & & \\
\hline & & & N. & $\%$ & N. & $\%$ & N. & $\%$ \\
\hline 1.5 & 1 & 33.33 & 2 & 66.67 & 0 & 0.00 & 3 & 100 \\
\hline 2.5 & 2 & 50.00 & 1 & 25.00 & 1 & 25.00 & 4 & 100 \\
\hline 3.5 & 2 & 50.00 & 1 & 25.00 & 1 & 25.00 & 4 & 100 \\
\hline 4.5 & 0 & 0.00 & 2 & 66.67 & 1 & 33.33 & 3 & 100 \\
\hline 5.5 & 1 & 25.00 & 2 & 50.00 & 1 & 25.00 & 4 & 100 \\
\hline 6.5 & 4 & 57.14 & 2 & 28.57 & 1 & 14.29 & 7 & 100 \\
\hline 7.5 & 11 & 68.75 & 0 & 0.00 & 5 & 31.25 & 16 & 100 \\
\hline 8.5 & 7 & 50.00 & 3 & 21.43 & 4 & 28.57 & 14 & 100 \\
\hline 9.5 & 7 & 63.64 & 1 & 9.09 & 3 & 27.27 & 11 & 100 \\
\hline 10.5 & 1 & 20.00 & 1 & 20.00 & 3 & 60.00 & 5 & 100 \\
\hline 11.5 & 3 & 75.00 & 0 & 0 & 1 & 25.00 & 4 & 100 \\
\hline
\end{tabular}

N.B: \% were correlated to the total number of children female in each duration range.

Statistical analysis of the effects of hepatitis $B$ vaccination duration on seropositivity to antiHBs, proved that the expression of Hepatitis Bs $\mathrm{Ab}$ titer in vaccinated children $<6$ years is significantly higher than that in vaccinated children $>6$ years (tables $4,5 \& 6$ ). Also there is high statistical significant negative correlation between Hepatitis Bs Ab titer among children and the time passed since the $3^{\text {rd }}$ dose of vaccination.

Table 4. Difference in the Mean (SD) of the expression of Hepatitis Bs Ab titer among vaccinated children group after $3^{\text {rd }}$ vaccination dose

\begin{tabular}{|c|c|c|c|c|c|}
\hline \multirow{3}{*}{$\begin{array}{c}\text { Hepatitis Bs Ab } \\
\text { titer }\end{array}$} & \multicolumn{3}{|c|}{ Vaccinated Children Group } & \multirow{3}{*}{$\begin{array}{c}\text { Kruskal Wallis } \\
\text { test }\end{array}$} & \multirow{3}{*}{ P-value } \\
\hline & $2-5$ years & $6-8$ years & $9-12$ years & & \\
\hline & N. (29) & N. (55) & N. (73) & & \\
\hline \multicolumn{6}{|l|}{ After $3^{\text {rd }}$ dose } \\
\hline Mean $\pm(S D)$ & $96.8(148.2)$ & $58.2(114.8)$ & $80.1(136.5)$ & $\chi^{2}=134.6$ & $<0.001 *$ \\
\hline Median & 32 & 11 & 11 & & \\
\hline
\end{tabular}


Table 5. Post vaccination results after full vaccination among children group

\begin{tabular}{|c|c|c|c|c|c|c|c|c|}
\hline \multirow{4}{*}{$\begin{array}{c}\text { Hepatitis Bs Ab } \\
\text { titer after } 3^{\text {rd }} \text { dose } \\
\text { of vaccination }\end{array}$} & \multicolumn{6}{|c|}{ Children Group } & \multirow{4}{*}{$\begin{array}{c}\text { Chi } \\
\text { Square } \\
\left(\chi^{2}\right)\end{array}$} & \multirow{4}{*}{ P-value } \\
\hline & \multicolumn{2}{|c|}{$2-5$ years } & \multicolumn{2}{|c|}{$6-8$ years } & \multicolumn{2}{|c|}{$9-12$ years } & & \\
\hline & Male & Female & Male & Female & Male & Female & & \\
\hline & $\mathbf{N}(\mathbf{1 5})$ & $\mathrm{N}(14)$ & $\mathbf{N}(28)$ & $\mathbf{N}(27)$ & $\mathbf{N}(39)$ & $\mathrm{N}(34)$ & & \\
\hline \multicolumn{9}{|l|}{ - ve test results } \\
\hline $\begin{array}{c}\text { Number } \\
(\%)\end{array}$ & $\begin{array}{c}6 \\
(40)\end{array}$ & $\begin{array}{c}5 \\
(35.7)\end{array}$ & $\begin{array}{c}15 \\
(53.6)\end{array}$ & $\begin{array}{c}16 \\
(59.3)\end{array}$ & $\begin{array}{c}24 \\
(61.5)\end{array}$ & $\begin{array}{c}18 \\
(52.9)\end{array}$ & 3.47 & $0.031 *$ \\
\hline \multicolumn{9}{|l|}{ Weak + ve results } \\
\hline $\begin{array}{c}\text { Number } \\
(\%)\end{array}$ & $\begin{array}{c}3 \\
(20)\end{array}$ & $\begin{array}{c}6 \\
(42.9)\end{array}$ & $\begin{array}{c}8 \\
(28.6)\end{array}$ & $\begin{array}{c}4 \\
(14.8)\end{array}$ & $\begin{array}{c}6 \\
(15.4)\end{array}$ & $\begin{array}{c}5 \\
(14.7)\end{array}$ & & \\
\hline \multicolumn{9}{|l|}{ Strong + ve results } \\
\hline $\begin{array}{c}\text { Number } \\
(\%)\end{array}$ & $\begin{array}{c}6 \\
(40) \\
\end{array}$ & $\begin{array}{c}3 \\
(21.4) \\
\end{array}$ & $\begin{array}{c}5 \\
(17.9)\end{array}$ & $\begin{array}{c}7 \\
(25.9) \\
\end{array}$ & $\begin{array}{c}9 \\
(23.1)\end{array}$ & $\begin{array}{c}11 \\
(32.4)\end{array}$ & & \\
\hline
\end{tabular}

* There is high statistical significant response to vaccination among childrens $2-5$ years more than that among children $>6$ years.

Table 6. Spearman's rho Correlation between the expression of hepatitis Bs Ab titer among children and the time passed since the $3^{\text {rd }}$ dose of vaccination

\begin{tabular}{ccc}
\hline Characteristics & $\begin{array}{c}\text { Correlation } \\
\text { coefficient (r) }\end{array}$ & P-value \\
\hline $\begin{array}{c}\text { Hepatitis Bs Ab titer after } 3^{\text {rd }} \text { dose Vs: } \\
\text { Time passed since the } 3^{\text {rd }} \text { dose of vaccination }\end{array}$ & -0.373 & $<0.001 *$ \\
\hline $\begin{array}{l}\text { There is high statistical significant negative correlation between Hepatitis Bs antibodies titer among } \\
\text { children and the time passed since the 3rd dose of vaccination. }\end{array}$
\end{tabular}

\section{DISCUSSION}

$\mathrm{HBV}$ infection is preventable with safe and effective vaccines that have been available since 1982. The vaccine is $95 \%$ effective in preventing chronic infections from developing, and is the first vaccine against a major human cancer. More than 160 countries have already added this vaccine to their routine immunization programs (5). The schedule adopted by Ministry of Health was three doses of yeast-recombinant hepatitis $B$ vaccine administered to all infants at 2, 4, 6 months to coincide with other compulsory vaccines (Diphtheria, Tetanus, Pertussis and oral polio (DPT- OPV) (5).
In our study negative antibody response were observed in 21 and $17 \%$ in male and female children respectively whom were vaccinated according to the official vaccination schedule and their age range was 2-5 years old (at the time samples were drawn). This negative percentages were increased to 27 and $29 \%$ in male and female children respectively whom age range was 6-8 years old. Finally in children with age range 9-12 years old the immune response negative percentages were 33 and $25 \%$ in male and female children respectively. The obtained finding is in agreement with those studies reported by Wildgrub et al. (6), Pongpithead and Assateerwait (7), Lin and 
Ou-xang (8) and Kuhil et al., (9). The results of a small study revealed that approximately onefourth of successfully vaccinated infants with anti- HBs $<10 \mathrm{mIU} / \mathrm{ml}$ by early adolescence fail to mount an anamnestic response to a booster dose of $\mathrm{HB}$ vaccine Whether booster doses of vaccine are needed for long term protection into late adolescence and adulthood need to be clarified (10). Wanget al., (11) cleared that their previous study suggests that routine booster vaccination may not be necessary to provide protection against chronic $\mathrm{HBV}$ infection before age 15 years. Also, El-Sawy and Mohamed (12) evaluated the longtermimmunogenicity and efficacy of HBV vaccination in children whose timelapse since last vaccination varied between 1 month and 5 years. They found that there were low initial anti-HBs concentrations and it declined rapidly over time. Puvacic et al., (13) reported that after five years of vaccination, long term immunogenicity of vaccinated children remained at $88.89 \%$. In a long study for 18 years, Yuen et al., (14) stated that the long-term immunogenicity and efficacy of hepatitis B virus (HBV) vaccination remain to be defined.

Sjogren (15) stated that the distinction between truenonresponse (after adequate immunization) and waning anti-HBs levels is important. The latter is notuncommon in populations in areas of the world with low endemicity for $\mathrm{HBV}$ infection. Data from subjects with waning anti-HBs levels show thatimmunologic memory may still protect these individuals against acute HBV infection or may prevent chronic infection with HBV for $<$ or $=10$ years after immunization.

The present study indicated that there was no differences between boys and girls concerning in levels of HBs $\mathrm{Ab}$. This agree with that obtained by $\mathbf{E l - S a w y}$ and Mohamed (12). But disagrees in part with some investigators, where McMahon et al., (16) stated that initial anti-HBs level in older age at vaccination and male sex were associated with persistence of higher anti-HBs levels at 15 years.

In conclusion, the most important overall findings emanating from this study were:
1. High seroprotection rate was elicited by hepatitis B vaccination especially in the young age groups.

2. There is high statistical significant negative correlation between Hepatitis Bs Ab titer among children and the time passed since the $3^{\text {rd }}$ dose of vaccination..

3. A booster dose of hepatitis B vaccine not needed until 6 years.

4. The study indicates that there is a trend of decreasing antibody level with increasing age, this could be noted from the significant differences between age groups.

\section{REFERENCES}

1. Ganem $D$ and Prince $A$ M (2004): Hepatitis B virus infection-natural history and clinical consequences. $N$ Eng $J$ Med.;350:1118-1129.

2. Tacket $C O$ (1999): Safety and immune response studies at a DNA vaccine encoding hepatitis B surface antigen delivered by a gene delivery device. Vaccine, 17: 2826 - 2829.

3. Robinson W $S$ (1995): "Hepatitis B virus and hepatitis D virus" In: Mandell G.L., Bennett J.E., Dolin R. eds. Principles and Practice of Infectious Disease, $4^{\text {th }}$ ed. New York, Churchill Livingstone, pp. 1406 1439.

4. Mahoney $F J$ and Kane $M$ (1999): "Hepatitis B vaccine" In: Plotkin S.A., Orenstein W.A., eds. Vaccines. $3^{\text {rd }}$ ed. Philadelphia, W.B. Saunders Company, pp. 158-182.

5. Mansour E, Abdul-Rahim S, Batouty $G$, Zaghloul I and Abdel-Hadi $S$ (1993): Integration of hepatitis B immunization in the Expanded Program onImmunization of the Child Survival Project. J Egypt Public Health Assoc.;68(5-6):487-494. 
6. Wildgrube $H$ J, Glassen M,Vonlohr $R$, Kurth $R$ and Brede HD (1984): Active immunization against hepatitis B. Dtch-Med Wochenschr, 109 (7): $246-250$.

7. Pongpipate D and Assateerawait N (1984): Vaccination against hepatitis $B$ virus infection in neonates. Helv Pediatr Acta.;39(3):231-239.

8. Lin X and Ou-xang (1999): Long term efficacy study of hepatitis B vaccination in newborns results at 11 years follow - up. Zhonghua Liu Xing Bing Xue ZaZhi.; 20 (3):141 - 147.

9. Kuhail $S$, El-Khodary $R$ and Ahmed $F$ (2000): Evaluation at the routine hepatitis B immunization program in Palestine. East Mediterr health J.;(6):864 - 869.

10. Dentinger C M, McMahon B J, Butler J $C$, Dunaway $C E$, Zanis $C L$ and Bulkow $L$ $R$ (2005): Persistence of antibody tohepatitis B and protection fromdisease among Alaska nativesimmunized at birth. PediatrInfect Dis J.;24(9):786-792.

11. Wang $J S$, Chen $H$ and Zhu $Q$ (2005): Transformation of hepatitis $B$ serologic markers in babies born to hepatitis B surface antigen positive mothers. World $J$ Gastroenterol.:11(23):3582-3585.

12. El-Sawy I H and Mohamed $O N$ (1999): Long term immunogenicityand efficacy of recombinant hepatitis B vaccine in Egyptian children. J. EasternMediterranean health.;5(5):922-932.

13. Puvacic S, Ravlija J, Puvacic $Z$ and Curic I (2005): Long termprotection after hepatitis B vaccination. Bosn $J$ Basic MedSci.; 5(3):50-53.

14. Yuen MF, Lim WL, Chan A O, Wong D $K$, Sum $S S$ and Lai C L (2004): 18-year follow-up study of aprospective randomized trial of hepatitis B vaccinations without booster doses in children. Clin Gastroenterol Hepatol.;2 (10): 941-945.

15. Sjogren $M \quad H$ (2005): Prevention of hepatitis $\mathrm{B}$ in non-responders to initial hepatitis B virus vaccination. Am J Med.;10:34-39.

16. McMahon B J, Bruden D L, Petersen KM, Bulkow $L R$, Parkinson $A J$ and Nainan $O$ (2005): Antibody levels and protection after hepatitis B vaccination: results of a 15-year follow-up. Ann Intern Med. ;42(5):333-341.

$$
\begin{aligned}
& \text { الملخص العربي } \\
& \text { تقييم فعالية لقاح التهاب الكبد الوبائي بي للأطفال في منطقة مصراتة، ليبيا }
\end{aligned}
$$

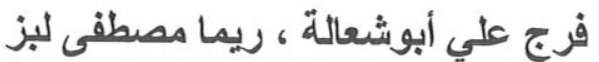

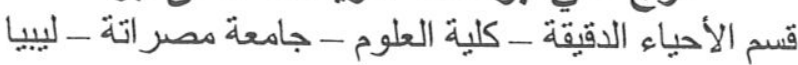

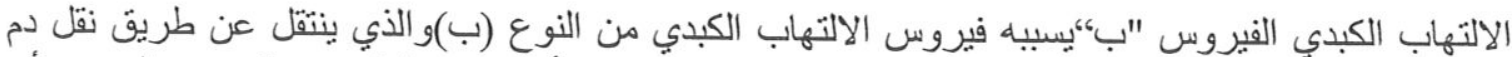

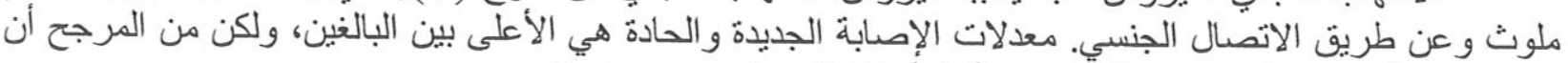

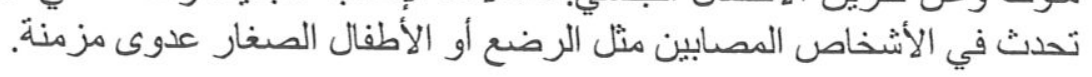

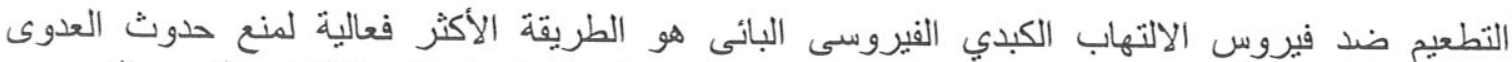

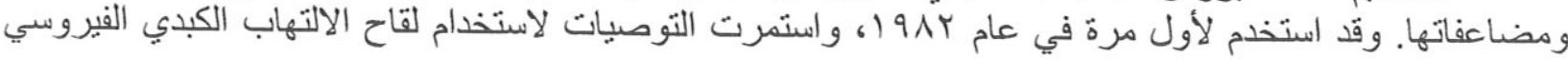
"ب" في استر اتيجية شاملة للقضاء على التى انتقال الفيروس.

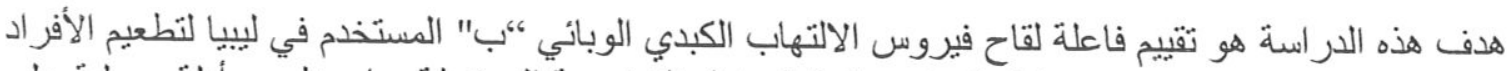

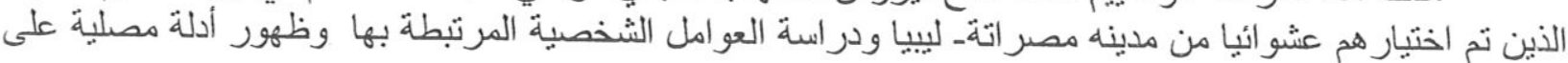




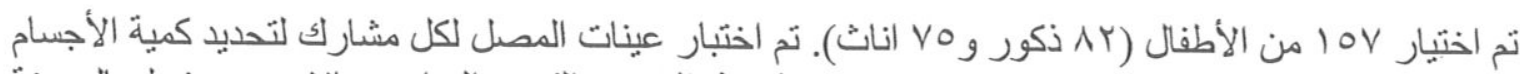

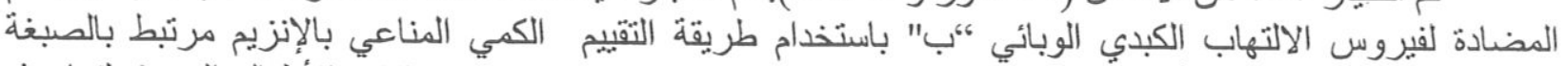

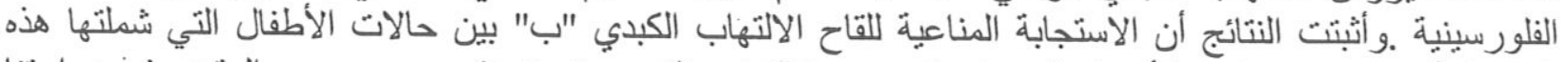

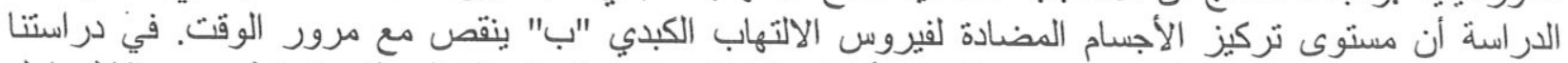

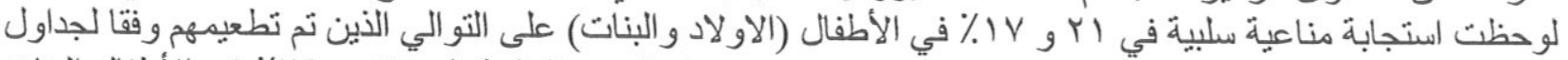

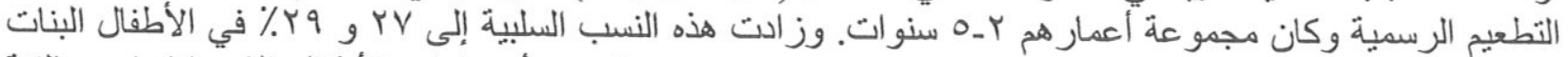

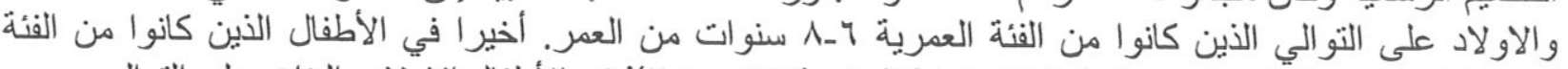

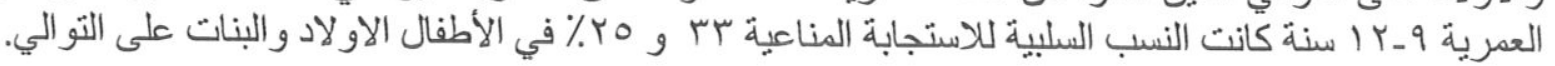

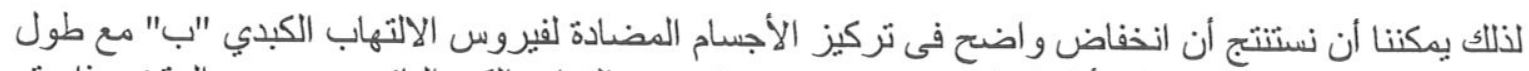

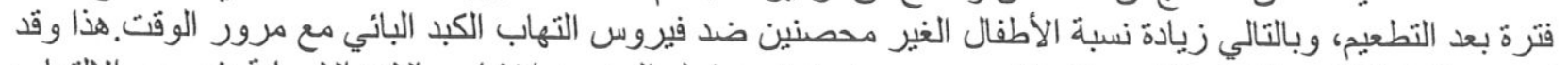

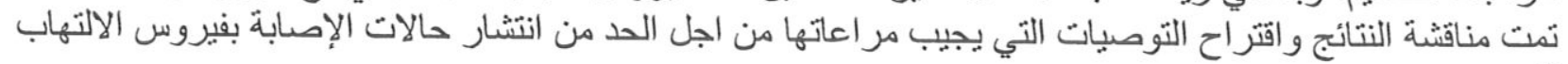

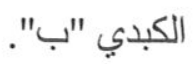

